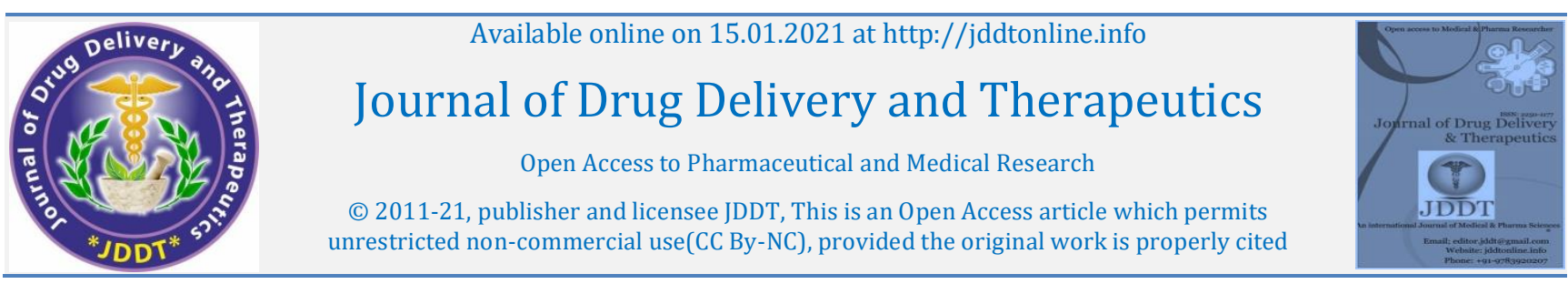

(C) 2011-21, publisher and licensee JDDT, This is an Open Access article which permits

Open Access Full Text Article

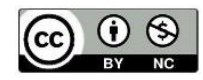

Review Article

\title{
A Review on Microsphere
}

\author{
Prafull Gavhane*, Madhuri T. Deshmukh, Abhijit N. Khopade, Vaibhavi V Kunjir, Rajkumar V Shete \\ Department of Pharmaceutics, Rajgad Dnyanpeeth's College of Pharmacy, Bhor, Pune, India
}

\section{Article Info:}

\section{Article History:}

Received 17 Oct 2020;

Review Completed 16 Dec 2020

Accepted 23 Dec 2020;

Available online 15 Jan 2021

Cite this article as:

Gavhane P, Deshmukh MT, Khopade AN, Kunjir

VV, Shete RV, A Review on Microsphere, Journal

of Drug Delivery and Therapeutics. 2021;

11(1):188-194

DOI: http://dx.doi.org/10.22270/jddt.v11i1.4501

*Address for Correspondence:

Prafull Gavhane, Department of Pharmaceutics,

Rajgad Dnyanpeeth's College of Pharmacy, Bhor,

Pune, India

\section{Abstract}

The microsphere is having free-flowing powder properties that are incorporate proteins and synthetic or natural polymer. This polymer is biodegradable in nature and particle size having less than $200 \mu \mathrm{m}$. Advanced drug delivery system has various advantages over the mainstream multi dose therapy. The microsphere's drug delivery systems are acceptable for attained delay or sustained release formulation with minimum risk of dose repeatability and small gastric habitation time. The present review provides a complete discussion of therapeutic aspects of the microsphere drug delivery system into deliberation of the required area for microparticulate, types of polymers used, method of preparation, type of microspheres in detail, parameters \& targeting of microspheres \& practical aspects of microspheres.

Keywords: Microspheres, bioavailability, types, classification, ideal properties, evaluation, etc.

\section{Introduction:}

The medication should be conveyed to correct focused on locales at a rate and fixation that license astounding restorative adequacy while least result and patient consistence during treatment. ([i])

Medication conveyance framework target medication to the particular body site which vastly affects the medical care framework ([ii])

The high level medication conveyance framework has a reason to disseminate the medication at a rate coordinated by the requirements of the body all through treatment and channel the dynamic element to the site of activity. Presently a day, no available medication conveyance framework act ideally accomplish all the predominant objectives yet honest endeavors have been made to accomplish them through new methodologies in medication conveyance. A few progressed drug conveyance frameworks have arisen encompassing the various courses of organization to accomplish controlled and focused on medication conveyance. ([iii]).

Microspheres are little circle molded particles which are having a measurement of about 1um to $100 \mathrm{um}$. They are free-streaming particles which are including manufactured and protein-polymer and they are having nature is biodegradable ([iv])
In the middle of the 1940s and 1960s, the possibility of synthetic microencapsulation innovation started as offbeat methods for conveying drugs. In the proceeded with pursuit for more refined frameworks' during the 1980s polymer/Membrane innovation came to be known at the bleeding edge. ([v])

Biodegradable and non-biodegradable polymers of microspheres have been investigated for deferred or controlled delivery trusts in the finishing up application. The most predominant quality of microparticles is the microphase separation morphology which blesses it with a defer change in medication discharge and furthermore debasement rate. ([vi])

\section{Ideal Properties of Microsphere: ([vii])}

- The potential to coordinate reasonably high groupings of the medication.

- Stability of the detailing after union with a clinically satisfactory shelf life of realistic usability.

- Controlled molecule size and dispersed in watery vehicles for infusion.

- Having Biocompatibility with a prohibited biodegradability.

- The propensity to compound adjustment.

- Control of medication discharge. 
- Control of medication discharge.

- Increase helpful adequacy and abatement the harmfulness

- Bioadsorbable.

Advantages: ([viii]) ([ix]) ([x])

- Masking of terrible order and repulsive tasting drug.

- Get better actual steadiness and gastric compound dependability.

- Better process aptitude (improved flowability, dispersibility).

- Less dosing recurrence, along these lines, increment patient consistence and abatement poisonousness.

- Reduced gastric variance.

- Minimize the first-pass metabolism.

- Improved biological half-life.

- Enhance bioavailability.

- Enhance restorative adequacy and delayed length of activity.

- Sustain and focused on medication conveyance framework.

- Easily infused into the body due to little measure and circle formed.

- They bear the cost of guard before after organization for the precarious medication.

- They shortened the convergence of the medication at a site other than the tissue or the objective organ.

\section{Disadvantage: ([xi]) ([xii])}

- Drug discharge from measurements structure differs with an assortment of variables like inalienable and outward factors, food, and the pace of move through the gut.

- The distinction in the delivery rate starting with one portion then onto the next.

- Controlled discharge arrangement normally having a high amount of medications contains veracity and any vanishing of the measurements structure discharge trademark it might show to bring about the development of conceivable poisonousness and treatment disappointment.

- Such measurement structures ought not be compacted or bitten.

- Short drug stacking (limit of half) for the controlled delivery measurement structure.

- Once managed it is difficult to eliminate the transporter totally from the body.

- Parental conveyance of microsphere may act together or structure edifices with the blood segment.

Types of Microspheres:
1. Bioadhesive microspheres: The bond of a medication to the film by utilizing the cement property can be characterized as attachment of waterdissolvable polymers. These sorts of microspheres give the site of activity for a drawn out home time. The dedication of the medication conveyance system to the mucosal layer like as nasal, rectal, rectal, buccal, visual, and so forth ([xiii]) Devotion should be clarified as adhering of the medication to the film by utilizing the staying property of the water-dissolvable polymers. Grip of the medication conveyance framework to the mucosal covering like nasal, visual, rectal, buccal, and so on can be named as bioadhesion. ([vii])

2. Floating microspheres: In floating type's microspheres, the microspheres stay light in the stomach without upsetting gastric discharging rate when mass thickness is lower than the gastric liquid. At the favored rate, the medication is free gradually, if the framework is coast on gastric liquid and increments gastric maintenance, and expands instability in plasma fixation. Moreover, it likewise limits the odds of unmistakable and unloading of portion. A solitary diverse way, it delivers a drawn out remedial impact and in this manner diminishes dosing frequencies ([xiv])

3. Radioactive microspheres: Radioactive microspheres are better than veins and get depleted in essential veins bed when they are approach across and having molecule size around 10-30 $\mathrm{nm}$. To prompt the interest of the tumor they are infused into the supply routes. At that point, these all circumstances radioactive microspheres pass on a high radiation portion to the focused on zones without harming the ordinary close by tissues. ([xv]) These radioactive microspheres transport portion in high radiation to focused zones without obliterating the typical tissues. Different kinds of radioactive microspheres are $\alpha$ producers, $\beta$ producers, $\gamma$ producers. ([xvi])

4. Mucoadhesive microspheres: Mucoadhesive microspheres are having a measurement of around 1$1000 \mathrm{~mm}$ and polymer comprising besides totally of a mucoadhesive or having a furthest covering of it. In normally, microspheres have the likely to be utilized for controlled and focused on delivery drug conveyance yet mucoadhesive mix attributes to microspheres have more preferences, e.g., clever assimilation and increment the bioavailability of the medications in view of volume proportion in a high surface, a great deal of close to contact with the bodily fluid layer, exact focusing of medication to the retention site accomplished by securing plant lectins, bacterial bonds, and antibodies, and so on, on the lower part of the microspheres. ([vii])

\section{Polymer used in the formulation of microspheres: ([vi])}

\section{1] Synthetic polymer}

\section{A] Biodegradable:}

- Polyalkyl cyno acrylates

- Polyanhydides

- Lactides and glycolides and their copolymer.

B] Non-biodegradable:

- Acrolein 
- Epoxy polymer

- PMMA

- Glycidyl methacrylate

2] Natural Materials

A] Carbohydrates

- Agaose

- Starch

- Carrageenan
- Chitosan

B] Chemically modified carbohydrate

- DEAE cellulose

- Poly (acryl) starch

- Poly (acryl) dextran

C] Proteins

- Collagens

- Gelatins

- Albumins

\section{Method of Preparation:}

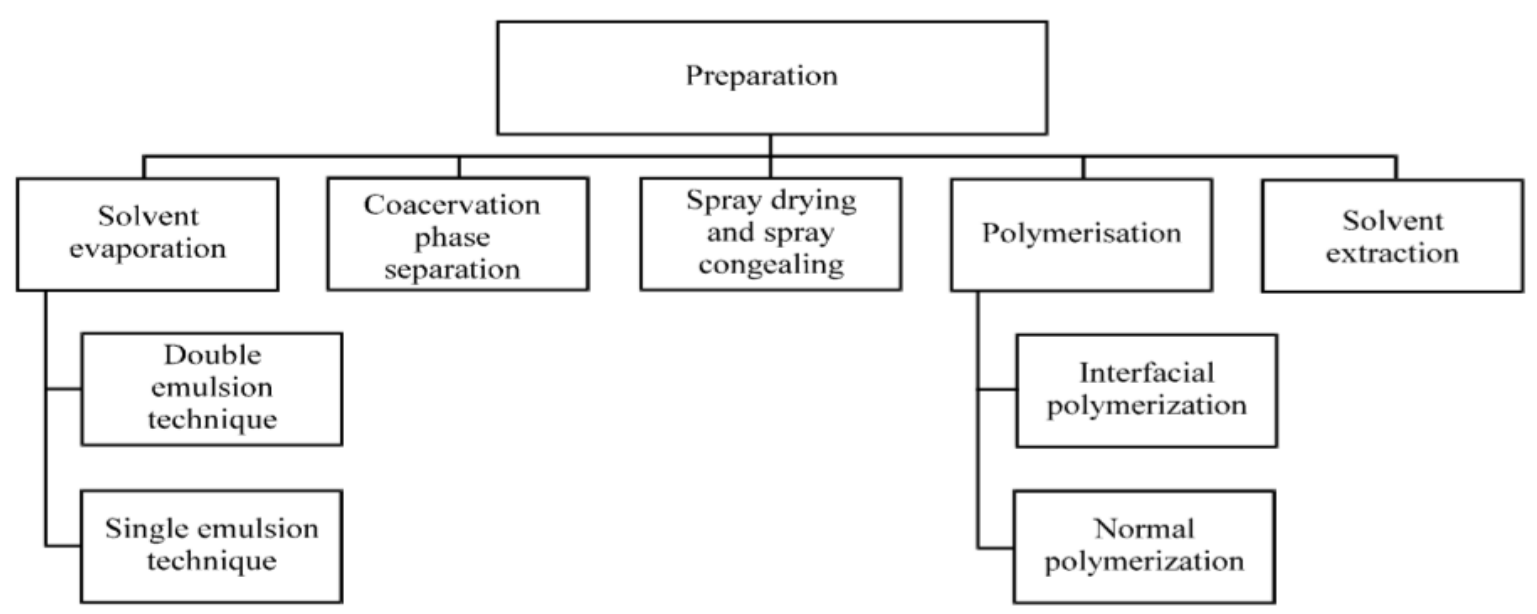

Figure 1: method of preparation of microspheres (Ganesan P \& 153-179.)

1. Single emulsion technique: The microspheres of normal polymers which are proteins and starches are detailed by a solitary emulsion procedure (Fig2). The common polymers are broken up/confined in fluid arrangement scattering is continued in the non-watery medium for example oil. From that point onward, cross-connecting of the confined globule is done likewise using temperature or by utilizing substance cross-linkers. The crossconnecting substance specialists used to like terephthalate chloride, formaldehyde, diacid chloride, glutaraldehyde, ([xvii]) ([xviii]).Cross-connecting by heat is valuable by adding the dispersing to prior warmed oil. For the thermolabile medications, heat denaturation isn't appropriate while the compound cross-connecting endures the downside of the extraordinary disclosure of dynamic fixing to synthetics whenever added at the hour of definition and afterward exposed to centrifugation, washing, and partition. ([xix])

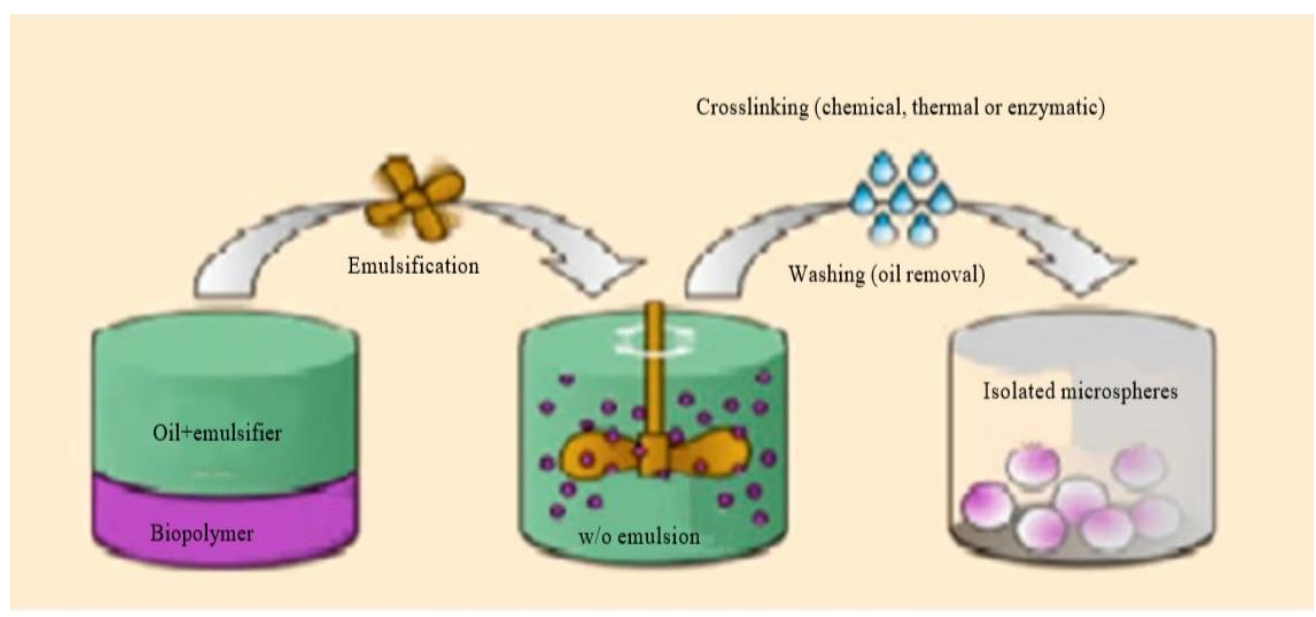

Figure 2: Single emulsion technique (Ganesan P \& 153-179.)

2. Twofold emulsion method: This cycle devours advancement of the twofold emulsions or the various emulsion of type $\mathrm{w} / \mathrm{o} / \mathrm{w}$ and is most phenomenal appropriate to the proteins, peptides, immunizations, and the water-solvent medications (Fig 3). In a lipophilic natural customary stage the fluid protein 
arrangement is disengaged, which is generally comprised of polymer arrangement that eventually epitomizes protein contained in the scattered watery stage. A fluid arrangement of PVA is added after the primary emulsion is then put for the homogenization. This outcome in the setup of twofold emulsion which is then appropriate to dissolvable expulsion by dissolvable dissipation keeping up the emulsion at consolidated weight or by mixing with the goal that the natural eliminate vanishes. Models are hydrophilic medications, for example, LHRH agonists, immunizations, and proteins. ([vii])

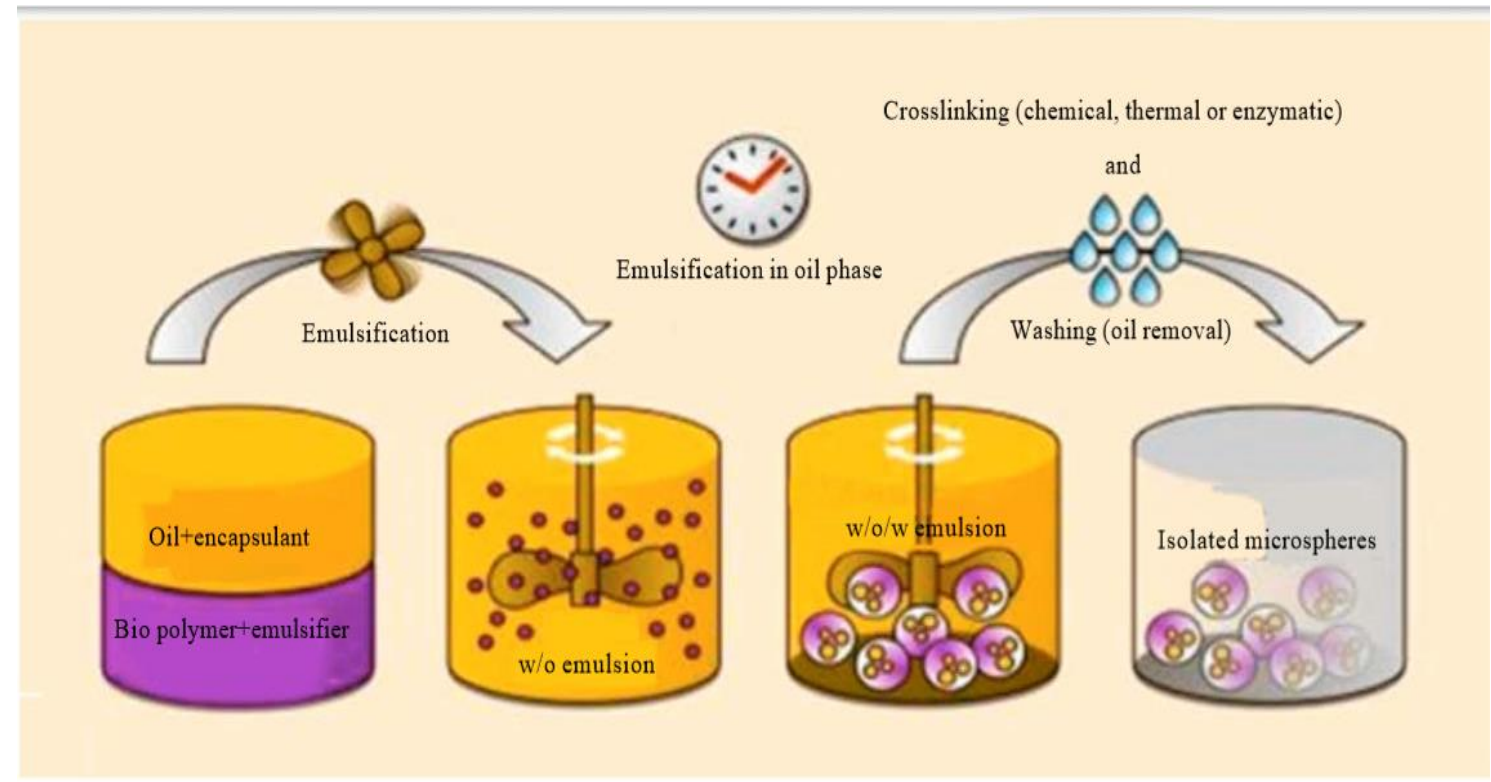

Figure 3: Double emulsion techniques (Ganesan P \& 153-179.)

\section{Polymerization method:}

\section{A) Normal polymerization:}

Performed, utilizing strategies, for example, mass, suspension precipitation, emulsion subatomic molecule polymerization measures. In the polymerization technique for mass, a monomer with an originator is warmed to begin polymerization. The originator is added to speed climb the response rate. At the point when the polymerization cycle during medication should be added, the polymer subsequently acquired is part into microspheres (Fig 4)

\section{B) Suspension polymerization:}

The suspension polymerization technique is executed in a constant stage by warming the monomer or combination of a monomer with standards as beads scattering. The beads might be containing an originator and different added substances. At low temperature, the emulsion and suspension polymerization can be executed, since the nonstop external stage is regularly warmed through the water to just vanish. ([vii])

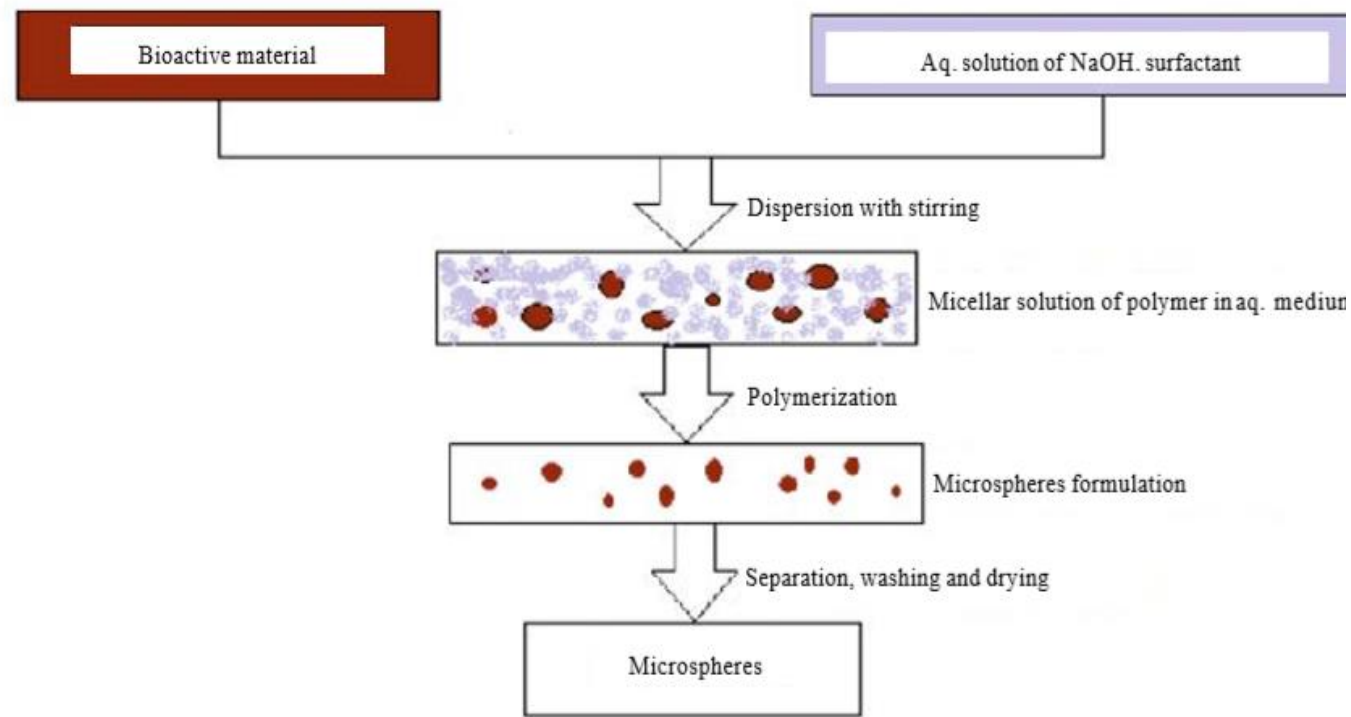

Figure 4: Polymerization methods (Ganesan P \& 153-179.) 


\section{Solvent evaporation:}

This cycle is done in the vehicle period of fluid detailing. The microcapsule film is discrete in the unstable dissolvable which insoluble with the vehicle period of fluid planning. A center texture that is microencapsulated is broken down in the arrangement of the covering polymer. Exhibit With the center texture blend is broken up in a fluid definition. The vehicle stage is acquiring a reasonable size microcapsule. At that point the blend is warmed if fundamental to vanish and the dissolvable for the polymer of the center texture is broken up in the polymer arrangement, around the center polymer become or make more modest in size or sum. Network type microcapsules are shaped when center texture is broken up in the arrangement of the covering polymer. The center texture is water-dissolvable just as solvent materials. $([\mathrm{xx}])([\mathrm{xxi}])([\mathrm{v}])$

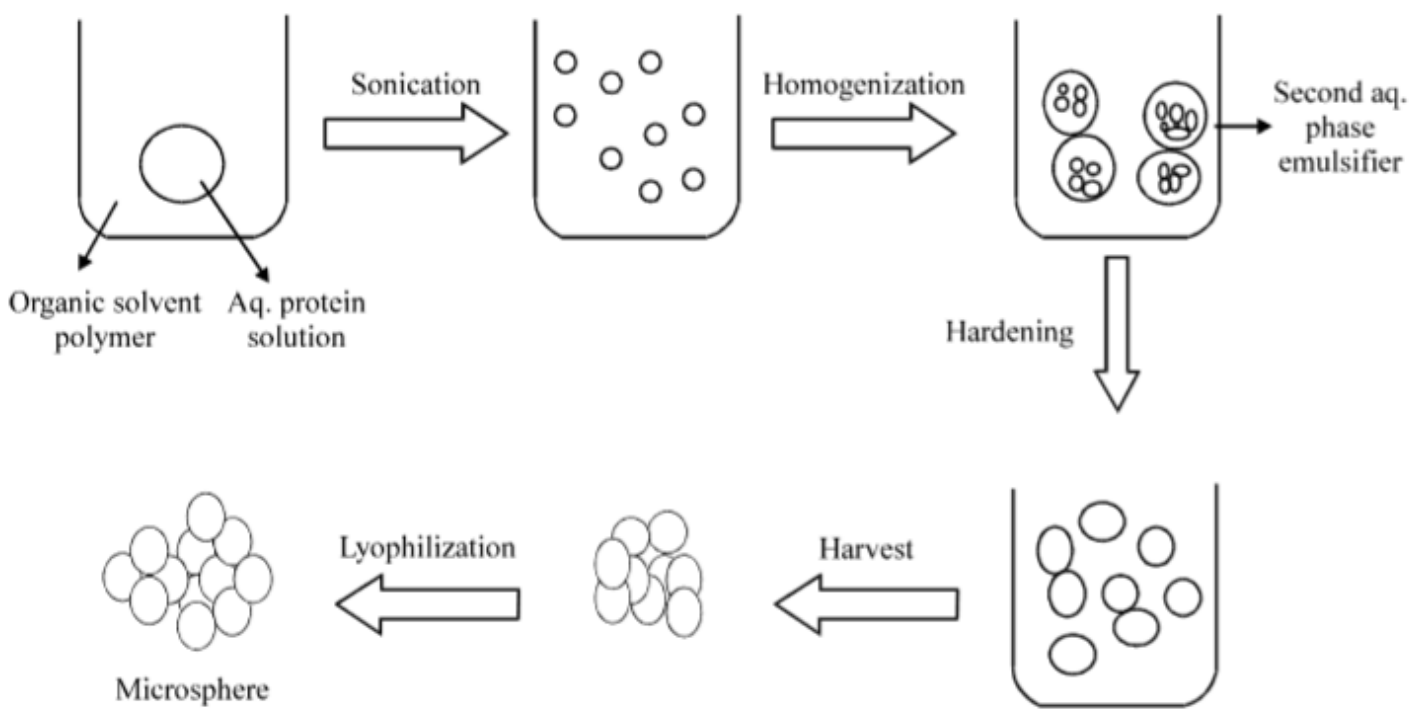

Figure 5: Solvent evaporation method (Ganesan P \& 153-179.)

\section{Solvent extraction:}

The dissolvable dissipation technique is utilized for extraction for the natural stage is taken out in the natural dissolvable to frame microspheres. These strategies incorporate natural solvents that are waterdissolvable like isopropanol. Extraction with water is taken out from the natural stage. This cycle lessens the cementing time for the microspheres. One contrast of the cycle incorporates the immediate expansion of the medication or protein to polymer natural arrangement. The dissolvable pace of disposal by extraction technique relies upon the warmth of water, the connection of the volume of emulsion to the dissolvability, and water figuration of the polymer. ([vii])

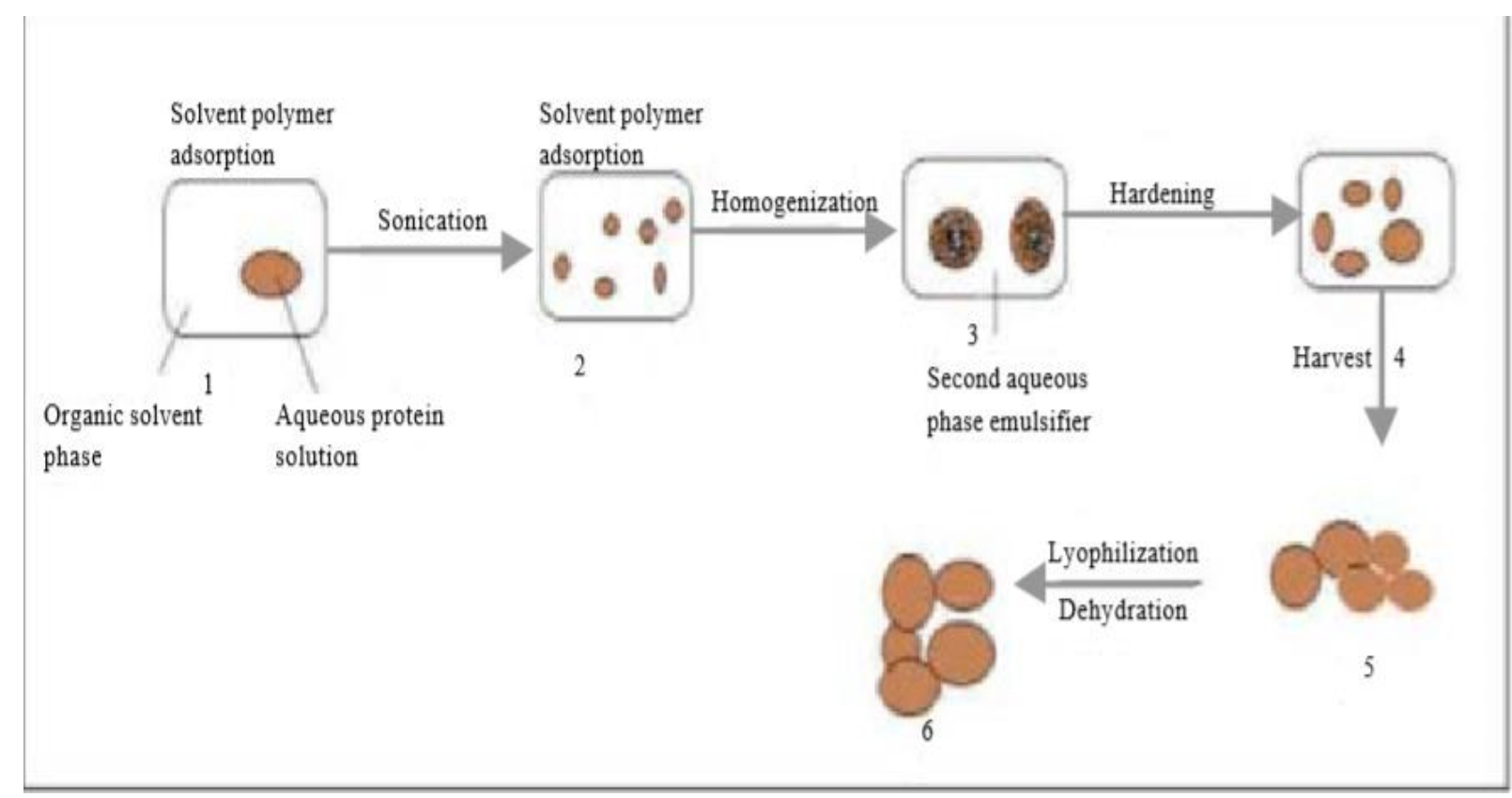

Figure 5: Solvent extractions (Ganesan P \& 153-179.) 


\section{Ionic gelation method:}

Ionic gelation technique is by and large utilized for the readiness of chitosan or alginate particulate frameworks for the arrival of diclofenac sodium. The $25 \%(\mathrm{w} / \mathrm{v})$ of diclofenac sodium was added to the 1.2 $\%(\mathrm{w} / \mathrm{v})$ watery arrangement of sodium alginate. An answer containing $\mathrm{Ca} 2+/ \mathrm{Al} 3+$ and acidic corrosive in chitosan arrangement in getting sorted out to the kept mixing of the total arrangement and after it was poured dropwise in the arrangement. Microspheres which were readied and these readied microspheres were kept in the first answer for inward invalidation for 24 hrs followed by filtration strategy for microspheres partition. In acidic $\mathrm{pH}$, the medication didn't deliver however a total arrival of medications has existed at 6.4-7.2 pH. ([vii])

\section{Evaluation Parameter for Microsphere:}

1. Molecule size and shape: For ordinary representation of microspheres the Scanning Electron Microscopy (SEM) and Light Microscopy (LM) systems are most broadly utilized. Both can have the option to find the outer structure and state of microspheres. In a twofold walled microsphere, the light microscopy (LM) manages the cost of a covering boundary. It estimated infinitesimally the microsphere structures can be imagined when the covering. A microsphere surfaces assessment and cross-separated after particles can permit the scanning electron microscopy (SEM). For twofold walled frameworks assessment, Scanning Electron Microscopy can be utilized. ([xxii])

2. Density determination: Multi-volume pycnometer is utilized for the thickness of the microspheres is estimated. In a cup the example is precisely said something is set in the multi-volume pycnometer. At a consistent weight helium is start in the chamber and they permit extension. Results are diminished in weight inside the get together in this development. At the point when two progressive readings of weight decrease at various proportion at that point introductory weight are note. From two weight readings, the volume can decide the thickness of the microspheres transporter ([xxiii])

3. Angle of contact: angle of contact is discovered the wetting property of a microparticle channel. The hydrophobicity or hydrophilicity term is inspecting microspheres' tendency. The interface of strong/air/water the point of contact should be estimated. The progressing and withdrawing point of contact are estimated by the addition of a bead in a roundabout cell mounted over the goal of an improved magnifying instrument. $20^{\circ} \mathrm{C}$ inside a moment of affidavit of microspheres the contact points are estimated ([xxiv])

\section{Electron spectroscopy for chemical analysis:}

The electron spectroscopy for substance investigation (ESCA) is pertinent for the surface science of the microsphere's assurance. A mean for the nuclear arrangement of the surface these stock the electron spectroscopy for the compound examination technique (ESCA). The assurance of surface corruption of the biodegradable microsphere is through the spectra. These spectra were gotten by utilizing ECSA. ([vii])

\section{Fourier transform-infrared spectroscopy:}

Corruption of the polymeric lattice of the transporter framework is dictated by utilizing the FT-IR. Rotated complete reflectance's (ATR) are estimating the explored surface of the microspheres. From the ATR cell, the IR bar is passed and they reflected commonly through the example to supply IR spectra chiefly of surface material. The surface arrangement of the microspheres relying on assembling methodology and condition, this data gives the ATR-FTIR. ([xxv])

\section{Entrapment efficiency:}

Lysate can decide the catch ability of the microspheres or the percent capture by permitting wash microspheres. According to monograph necessity, the lysate is then exposed to the assurance of dynamic constituents. The following equation is used for the calculation of encapsulation efficiency:

$$
\% D E E=\frac{\text { Estimated drug content }}{\text { Therotical percent drug content }} \times 100
$$

\section{In-Vitro Methods}

IN-VITRO technique is the exploratory strategy in which decide the delivery attributes and penetrability of a medication. The quantity of in-vivo and in-vitro strategies has been accounted for this reason. Quality control method in drug creation or item advancement is utilized In-vitro drug discharge examines. Characterize conditions are fundamental when delicate and reproducible information are gotten from physic synthetically and hydrodynamically. This mechanical assembly utilized different specialists for shifting plan and under fluctuating conditions; these conditions rely on the application and state of the measurement structure improvement.

\section{Conclusion:}

The microspheres are a very good option for the drug delivery system compare to other types of drug delivery systems because microspheres are having the good advantages of better patient compliance and specificity of targeting. Microsphere drug delivery system is an effective and safe drug delivery and these deliveries utilize in different areas such as specific targeting of a drug, floating and vaccine delivery, etc. Preparation methods and prepare microspheres evaluation are broadly present with effective availability. Microspheres are not only delivered the drug but they play a major role in imaging tumors, detecting the biomolecular interaction, and for treatment of cancer and hence in the next generation the microspheres are playing a major role in the advancement of the medical field. 


\section{References:}

${ }^{\text {i }}$ Varde NK, Pack DW. Microspheres for controlled release drug delivery. Expert opin biol ther. 2004; 4(1): 35-51.

ii Tadwee IK, Shahi S, Thube M. "Review on Microspheres". International Journal of Pharmaceutical Research \& Allied Sciences. $2011 ; 1(1): 24-33$.

iii Maincent P, Verge RL, Sado P, Couvreyr P, Devissaguet JP. Disposition kinetics and oral bioavailability of vincamine-loaded polyalkyl cyanoacrylate nanoparticles. Journal of pharmaceutical science. 1986; 75(10): 955-958.

${ }^{\text {iv }}$ Mahale MM, Saudagar RB. Microsphere: A review. Journal of drug delivery and therapeutics. 2019; 9(3-s): 854-856.

${ }^{v}$ Jain N.K. Controlled and novel drug delivery. CBS Publication, $20144^{\text {th }}$ ed, India, pp. 236-237.

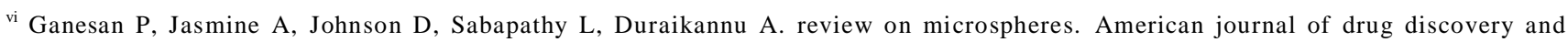
development. 2014; 4(3): 153-179.

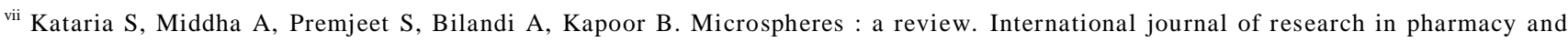
chemistry. 2011;1(4): 1184-1198.

viii Meena KP, Dangi JS, Samal PK, Namdeo KP. Recent advance in microspheres manufacturing technology. International journal of pharmacy and technology. 2011;3(1): 854-893.

${ }^{\text {ix }}$ Kadam NR, Suvarna V. Microspheres: A brief review. Asian journal of biomedical and pharmaceutical science. 2015 ; 5(47): 13-19.

${ }^{x}$ Nikam VK, Gudsoorkar VR, Hiremath SN, Dolas RS, Kashid VA. Microspheres - a novel drug delivery system: An overview. International journal of pharmaceutical and chemical science. 2012; 1(1): 113-128.

${ }^{x i}$ Bansal H, Kaur P, Gupta A. Microspheres: method of preparation and application; a comparative study. International journal of pharmaceutical science review and research. 2011; 10(1): 69-78.

xii Thanou M, Nihot MT, Jansen M, Verchoef JC, Junginger HE. Mono-n-carboxymethyl chitosan (MCC), a polyampholytic chitosan derivative, enhance the intestinal absorption of low molecular weight heparin across intestinal in vitro and in vivo. Journal of pharmaceutical science. $2001 ; 90(1): 38-46$.

xiii Jain N.K. Controlled and novel drug delivery. CBS Publication: $4^{\text {th }}$ ed, India 2014, pp. 236-237.

${ }^{\text {xiv }}$ Lachman LA, Liberman HA, Kanig JL. The theory and practical and practical of industrial pharmacy. Varghese publishing house, $3{ }^{\text {rd }}$ ed, Mumbai, India, 1991, pp. 414-415.

${ }^{x v}$ Amsden BG, Goosen MF. An examination of factors affecting size, distribution and releasecharecteristics of polymer microbeads made using electerostatics. Journal of controlled release, 1997; 43(1997): 183 -196.

${ }^{\text {xvi }}$ Saralidze K, Koole LH, Knetsch LW. Polymeric microspheres for medical application. Materials. 2010; 3: $3537-3564$.

xvii Vasir JK, Tambwekar K, Garg S. Bioadhesive microspheres as a controlled drug delivery system. International journal of pharmaceutics. 2003, 255(2003): 13-32.

xviii Trivedi P, Verma AM, Garud N. Preparation and characterization of aceclophenac microspheres. Asian journal of pharmaceutics. 2008; 110-115.

xix Schugens C, Laruelle N, Nihant N, Grandfils C, Jerome R. Effect of the emulsion stability on the morphology and porosity of semicrystalline poly 1-lactide microparticles prepared by w/o/w double emulsion-evaporation. Journal of controlled release. 1994; 32(1994): 161-176

${ }^{x x}$ Anande N, Jain S, Jain N. Con- A conjugated mucoadhesive microspheres for the colonic delivery of diloxanide furoate. International journal of pharmaceutics. 2008; 359(2008): 182-189.

${ }^{x x i}$ Dutta P, Struti J, Patra N, Bhanojirao ME. Floating microsphere: recent trends in the development of gastroretentive floating drug delivery system. International journal of pharmaceutical science and nanotechnology. 2011; 4(1): 1296-1306.

xxii Bodmeier R, Chen H. Preparation and characterization of microspheres containing the anti- inflammatory agents, indomethacin, ibuprofen and ketoprofen. Journal of controlled release. 1989; 10(1989): 167-175.

${ }^{x x i i i}$ Sinha VR, Agrawal MK, Kumria R. Influence of formulation and excipient variables on the pellet properties prepared by extraction spheronization. Current drug delivery. 2005; 2(1): 1-8.

xxiv Kawashima Y, Niwa T, Takeuchi H, Hino T, Itoh Y. Charecterization of polymorphs of trabilast anhydrate and tranilast monohydrates when crystallized by two solvent change spherical crystallization techniques. Journal of pharmaceutical science. $1991 ; 80(5): 472-478$.

${ }^{x x v}$ Tanala W, Akito E, Yoshida K, Terada T, Ninomiya H. US Patent. US 4059686. 1977. 